\title{
SOCIOECONOMIC CONDITIONS IN MDR AND XDR TUBERCULOSIS
}

\author{
Bhumika Madhav'1, Jayalakshmi T. K2, Aparnaiyer ${ }^{3}$
}

${ }_{1}^{1}$ Registrar, Department of Pulmonology, Apollo Hospitals, Navi Mumbai, Maharashtra.

2 Senior Consultant Pulmonologist, Department of Pulmonology, Apollo Hospitals, Navi Mumbai, Maharashtra.

${ }^{3}$ Consultant Pulmonologist, Department of Pulmonology, Apollo Hospitals, Navi Mumbai, Maharashtra.

\section{BACKGROUND}

ABSTRACT

Socioeconomic conditions can lead to the emergence of drug resistant tuberculosis. Aim of this study was to measure socioeconomic conditions in MDR and XDR tuberculosis.

\section{MATERIALS \& METHODS}

This is a descriptive study. 26 patients who were diagnosed with drug resistance were enrolled and subjected to a questionnaire which was later assessed. Most of the patients belonged to the lower socioeconomic status. We studied the living conditions, educational status, area of residence, cross ventilation, exposure to tuberculosis in friends and family, past history of tuberculosis treatment.

\section{RESULTS}

$76 \%$ of the patients belonged to the younger age group. $46 \%$ of the patients lived in overcrowded conditions, and poorly cross ventilated homes. $69 \%$ of the patients had past history of tuberculosis and $63 \%$ of primary MDR/XDR patients had history of contact to patients suffering from tuberculosis.

\section{CONCLUSION}

Unless living conditions that can spread tuberculosis are tackled, the scourge of tuberculosis cannot be eliminated in our country.

\section{KEYWORDS}

Tuberculosis, Multi Drug Resistant Tuberculosis, Socio-economic Factors.

HOW TO CITE THIS ARTICLE: Madhav B, Jayalakshmi TK, Aparnaiyer. Socioeconomic conditions in MDR and XDR tuberculosis. J. Evolution Med. Dent. Sci. 2018;7(10):1285-1288, DOI: 10.14260/jemds/2018/293

\section{BACKGROUND}

Socio economic factors play an important role in development and spread of pulmonary tuberculosis. Inadequate and incomplete treatment and poor treatment compliance has led to an increased drug resistance.[1]

According to WHO Global tuberculosis report 2017, In 2016, 6.3 million new cases of TB were reported equivalent to $61 \%$ of the estimated incidence of 10.4 million; the latest treatment outcome data show a global treatment success rate of $83 \%$. TB is the ninth leading cause of death worldwide. In 2016, there were an estimated 1.3 million TB deaths among HIV negative people.[2]

Drug-resistant TB is a continuing threat. In 2016, there were 600,000 new cases with resistance to rifampicin. There were 490,000 cases of multidrug-resistant TB emerging in 2016 and an additional 110000 cases that were susceptible to isoniazid but resistant to rifampicin which is the most effective first-line anti-TB drug. The countries with the largest numbers of Drug resistant TB cases (47\% of the global total) were China, India and the Russian Federation. ${ }^{[2]}$

In new and previously treated for MDR TB cases, the global averages were $7.3 \%$ and $14 \%$, respectively.[3]

'Financial or Other Competing Interest': None.

Submission 14-12-2017, Peer Review 14-02-2018,

Acceptance 20-02-2018, Published 05-03-2018.

Corresponding Author:

Dr. Jayalakshmi T. K,

\#405, Jasmine, Neelkanth Gardens,

Govandi East, Navi Mumbai,

Maharashtra.

E-mail:jaiclinic@gmail.com

DOI: $10.14260 /$ jemds $/ 2018 / 293$
Globally success rate for MDR-TB treatment according to data was $48 \%$.

Crowded and poorly ventilated living and working environments often associated with poverty can directly lead to tuberculosis transmission. Malnourishment is an important risk factor which can develop active tuberculosis. Poverty can lead to poor general health knowledge which leads to risk of exposure to several tuberculosis risk factors, such as HIV, smoking and alcohol abuse.[4],[5]

\section{Aims and Objectives}

To list the socio-economic conditions in patients with MDR/XDR Tuberculosis in tertiary care hospital in Navi Mumbai.

\section{MATERIALS AND METHODS}

26 patients diagnosed as MDR (23) or XDR (3) tuberculosis coming to tertiary care Hospital were asked a detailed questionnaire regarding the socio-economic conditions attributing to MDR and XDR tuberculosis and the following results were obtained. This is a descriptive study.

\section{RESULTS}

$76 \%$ of the Patients belonged to lower socioeconomic class belonging to the low-income group. $73 \%$ belonged to the unskilled class of employment and were the sole working members of the household and $89 \%$ of the unskilled class of employment lost their employment due to the disease.

$46 \%$ of the patients lived in over-crowded, unhygienic conditions, and poorly cross ventilated homes. 
$33 \%$ of the patients had Family members who had Pulmonary Tuberculosis in the past. $50 \%$ of the patients had close contact with other TB patients in the past. $69 \%$ of the patients had past history of tuberculosis. $63 \%$ of primary
MDR/XDR patients had history of contact to patients suffering from tuberculosis.

We obtained the result as follows which is illustrated in the tables below.

\begin{tabular}{|c|c|c|c|c|c|c|}
\hline \multicolumn{2}{|c|}{ Educational Status } & \multicolumn{3}{|c|}{ Employment } & \multicolumn{2}{|l|}{ Income } \\
\hline Grade & Percentage & \multirow{2}{*}{ Class } & \multirow{2}{*}{ Percentage } & \multirow{2}{*}{\begin{tabular}{|c|} 
Impact of the Disease \\
to the Employment
\end{tabular}} & \multirow{2}{*}{ Class } & \multirow{2}{*}{ Percentage } \\
\hline Illiterate & $4 \%$ & & & & & \\
\hline Middle school & $27 \%$ & Unskilled & $73 \%$ & $\begin{array}{l}89 \% \text { out of the group lost } \\
\text { their source of income }\end{array}$ & Low income group & $76 \%$ \\
\hline High school & $31 \%$ & Skilled & $4 \%$ & Lost the source of income & Middle income group & $23 \%$ \\
\hline Graduation & $38 \%$ & $\begin{array}{c}\text { Semi- } \\
\text { Professional } \\
\end{array}$ & $23 \%$ & $\begin{array}{l}66 \% \text { of the group lost } \\
\text { their source of income }\end{array}$ & High income group & None \\
\hline Post-Graduation & None & \multirow{2}{*}{ Professional } & \multirow{2}{*}{ None } & & \multirow{2}{*}{ Average Income } & \multirow{2}{*}{$\begin{array}{c}\text { Rs. } 2500 \text { to Rs } \\
10000 \text { per } \\
\text { month }\end{array}$} \\
\hline Others (Diploma) & None & & & & & \\
\hline
\end{tabular}

${ }^{*} 84 \%$ of the Patients lost their employment after being diagnosed as MDR/XDR tuberculosis. Out of which $76 \%$ of the patients belonged to the age group of 12 to $35.62 \%$ had completed high school and $38 \%$ were graduates.

\begin{tabular}{|c|c|c|c|c|c|c|c|c|}
\hline $\begin{array}{c}\text { Sr. } \\
\text { No. }\end{array}$ & $\begin{array}{c}\text { Type of } \\
\text { House }\end{array}$ & $\%$ & $\begin{array}{c}\text { Number of } \\
\text { Windows }\end{array}$ & $\begin{array}{c}\text { No of } \\
\text { Doors }\end{array}$ & $\begin{array}{c}\text { Exhaust Fan and } \\
\text { Cross Ventilation }\end{array}$ & $\begin{array}{c}\text { Toilet and } \\
\text { Sewage }\end{array}$ & $\begin{array}{c}\text { Sanitation } \\
\text { (Per sq. feet) }\end{array}$ \\
\hline 1 & Kuccha (2) & $8 \%$ & 1 & 1 & $\begin{array}{c}\text { No Cross } \\
\text { Ventilation }\end{array}$ & $\begin{array}{c}\text { Common toilet } \\
\text { outside }\end{array}$ & Poor & $300-450$ \\
\hline 2 & Pucca (24) & & & & & & & \\
\hline A & Chawl (10) & $38 \%$ & 1 & 1 & $\begin{array}{c}\text { No Cross } \\
\text { Ventilation }\end{array}$ & $\begin{array}{c}\text { Common toilet } \\
\text { outside }\end{array}$ & Poor & $450-750$ \\
\hline B & 1 Hall Kitchen (10) & $38 \%$ & $2-3$ & 1 & 1 Exhaust & Toilet Inside & Average & $600-850$ \\
\hline C & $\begin{array}{c}\text { 1 Hall, Kitchen, } \\
\text { Bedroom (4) }\end{array}$ & $15 \%$ & 3 & 2 & 1 Exhaust & Toilet Inside & Average & $800-1000$ \\
\hline \multicolumn{78}{|c|}{ Table 2. Housing, Ventilation and other Contributing Factors. } \\
\hline
\end{tabular}

${ }^{*} 46 \%$ of the patients who lived in kuccha house and chawl lived in overcrowded areas with very poor sanitation. The house had no cross ventilation.

$* 25 \%$ out of these patients lived near the industrial area with very poor hygiene in the neighbourhood.

\begin{tabular}{|c|c|c|c|}
\hline Sr. No. & Contact to Tuberculosis & Number & Percentage \\
\hline 1 & No contact & 13 & 30 \\
\hline 2 & Family & 6 & $4 \%$ \\
\hline 3 & Friends & 1 & $4 \%$ \\
\hline 4 & Co-workers & 1 & $4 \%$ \\
\hline 5 & Neighbour's and others & 1 & \\
\hline \multicolumn{2}{|c|}{ Table 3. Contact History } \\
\hline
\end{tabular}

* $42 \%$ Patients were Primary MDR patients

*1 patient out of 26 was Primary XDR.

\begin{tabular}{|c|c|c|c|}
\hline Sr. No. & Previous History & Number & Percentage \\
\hline 1 & No history of pulmonary tuberculosis & 8 & $31 \%$ \\
\hline 2 & Completed Treatment in the past & 6 & $23 \%$ \\
\hline 3 & Treatment Failure & 2 & $31 \%$ \\
\hline 4 & Relapse & $7 \%$ \\
\hline \multicolumn{2}{|c|}{ Table 4. Previous History of Pulmonary Tuberculosis } \\
\hline
\end{tabular}

*31\% were Primary drug resistant tuberculosis

*63\% Of Primary MDR/ XDR patients had History of contact to patients suffering from Tuberculosis.

\begin{tabular}{|c|c|c|c|}
\hline Sr. No. & Diet & Number & Percentage \\
\hline 1 & Vegetarian & 6 & $23 \%$ \\
\hline 2 & Non-Vegetarian & 20 & $77 \%$ \\
\hline \multicolumn{2}{|r|}{ Table 5. Nutritional Status } \\
\hline
\end{tabular}

*20\% of the MDR/XDR patients taking proper treatment Expired.

*1 Patient was evicted from her Husband's house due to the Disease.

${ }^{*} 10$ out of $26(36 \%)$ patients felt the social stigma and felt isolated in the community. 


\section{DISCUSSION}

There is a high TB burden in areas of chronic poverty and malnutrition. According to WHO 2017 Report, tuberculosis control in low and middle income countries requires action not only on the diagnosis and treatment but also on the social determinants which have caused an increase in tuberculosis burden.[2]

Social factors causing an increase in the disease has been studied worldwide. In our study, $62 \%$ had completed high school and $38 \%$ were graduates. $73 \%$ belonged to the unskilled class of employment and were the sole working members of the household and $89 \%$ of the unskilled class of employment lost their employment due to the disease. $76 \%$ of the Patients belonged to lower socioeconomic class belonging to the low income group. One such study done in Brazil which showed similar results, where the disease was affecting the poorer social groups strongly.[6] Another study which was done in New York city showed tuberculin positivity present in $5.5 \%$ in the area of highest socioeconomic status versus $22.4 \%$ in the lowest, thus indicating increased disease process in lower social groups. ${ }^{[7]}$ There was one more study from Liverpool, England which showed increased notification rates with higher tuberculosis rates in the economically backward sections of the society.

TB is more common in urban than in rural areas proving to be a threat in rapidly developing slum sector in the urban areas, Data from WHO TB Global report 2017 shows that there are almost 1 billion people living in urban slums in developing countries and annual population growth in Asia and Africa projected is $2.4 \%$, Urbanization has contributed to higher incidence of TB and initiating anti TB strategy becomes very difficult. The poor living conditions of many urban communities that suffer a high burden of TB particularly, overcrowding and poor ventilation in homes, workplaces, recreational spaces, and health facilities cause high rates of transmission.[2],[8],[9],[10] In our study, 46\% of the patients who lived in kuccha house and chawl lived in overcrowded areas with very poor sanitation. The house had no cross ventilation. $25 \%$ out of these patients lived near the industrial area with very poor hygiene in the neighbourhood.

TB illness can further exacerbate poverty, food insecurity, and malnutrition. Alleviating the poverty and improving the food security of these populations may reduce their TB burden.

In our study $84 \%$ of the Patients lost their employment after being diagnosed as MDR/XDR tuberculosis. Out of which $76 \%$ of the patients belonged to the age group of 12 to 35 which is the working class of the society. There was a study done in Poland which showed a higher Persistent unemployment increases poverty and its accompanying social pathologies, and keeps TB rates high. This can be prevented by accelerated economic growth and investment, which are required to reduce unemployment. One study done in South Africa reported that largest part of TB treatment cost was due to income loss due to loss of employment which increased the financial burden of other family members. [11]

In our study $33 \%$ of the patients had Family members who had Pulmonary Tuberculosis in the past. In our study $50 \%$ of the patients had close contact with other TB patients in the past. $69 \%$ of the patients had past history of tuberculosis. $63 \%$ of primary MDR/XDR patients had history of contact to patients suffering from tuberculosis. $42 \%$
Patients were Primary MDR patients. 1 patient out of 26 was Primary XDR. One review on contact investigations of tuberculosis cases in low and middle income countries showed that the prevalence of active tuberculosis among contacts of MDR or XDR tuberculosis was higher.[12]

$20 \%$ of the MDR/XDR patients taking proper treatment Expired. 1 Patient was evicted from her Husband's house due to the Disease. 10 out of $26(36 \%)$ patients felt the social stigma and felt isolated in the community. There have not been too many studies highlighting tuberculosis as a social stigma, however a few literature has studied about it along with social stigma of other infectious diseases. Research generally shows how stigma has an impact on individuals and communities, including delays in seeking health care, treatment and management.[13]

\section{CONCLUSION}

Overcrowding, poor sanitation, family history of tuberculosis, lower socioeconomic class, poorly ventilated areas of living and work are factors which were seen in our patients of multi drug resistance tuberculosis. A concerted effort needs to be made to improve standards of living and hygiene particularly in crowded urban slums. Merely treating the cases of TB and early diagnosis will not help to control the menace of MDR tuberculosis. The poor hygiene or living standards of one section of society will place all at high risk as the mycobacterium spreads across boundary walls and does not differentiate between the poor and the rich.

\section{REFERENCES}

[1] Zai S, Haroon T, Tahir K, et al. Socioeconomic factors contributing to multidrug-resistant tuberculosis (MDR-TB). J Biomed Sci and Res 2010;2(4):279-83.

[2] Global TB report 2017, World Health Organisation.

[3] World Health Organization. A global action framework for TB research in support of the third pillar of WHO's End TB Strategy. Geneva: World Health Organization, 2015. http://www.who.int/tb/publications/globalframeworkresearch/en/, accessed 8 August 2017.

[4] Udwadia ZF. India's multidrug-resistant tuberculosis crisis. Ann N Y Acad Sci 2001;953:98-105.

[5] Guidelines on programatic management of drug resistant tuberculosis in India-May 2012.

[6] Santos MLSG, Vendramini SHF, Gazetta CE, et al. Poverty: socioeconomic characterization at tuberculosis. Rev Lat Am Enfermagem 2007;15 Spec No:762-7.

[7] Cantwell MF, McKenna MT, McCray E, et al. Tuberculosis and race/ethnicity in the United States: Impact of socio-economic status. Am J Respir Crit Care Med 1998;157(4 Pt 1):1016-20.

[8] Reichmann LB, O’Day R. Tuberculosis infection in a large urban population. Am Rev Respir Dis 1978;117(4):705-12.

[9] Corbett EL, Bandason T, Cheung YB, et al. Prevalent infectious tuberculosis in Harare, Zimbabwe: burden, risk factors and implications for control. Int J Tuberc Lung Dis 2009;13(10):1231-7.

[10] Lonnroth K, Raviglione M. Global epidemiology of tuberculosis: prospects for control. Semin Respir Crit Care Med 2008;29(5):481-91. 
[11] Foster N, Vassall A, Cleary S, et al. The economic burden of TB diagnosis and treatment in South Africa. Social Science \& Medicine 2015;130:42-50.

[12] Fox GJ, Barry SE, Britton WJ, et al. Contact investigation for tuberculosis: a systematic review and meta-analysis. Eur Respir J 2013;41(1):140-56.
[13] Craig GM, Daftary A, Engel N, et al. Tuberculosis stigma as a social determinant of health: a systematic mapping review of research in low incidence countries. Int J Infect Dis 2017;56:90-100. 